\title{
Cholangiocarcinoma Presenting as Humoral Hypercalcemia of Malignancy: A Case Report and Literature Review
}

\author{
Burak Erdinc $^{1}$, Preethi Ramachandran ${ }^{2}$, Ruchi Yadav ${ }^{3}$, Sonu Sahni ${ }^{1,4,5}$, Gardith Joseph 6, 3 \\ 1. Internal Medicine, Brookdale University Hospital and Medical Center, Brooklyn, USA 2. Oncology, Brookdale \\ University Hospital and Medical Center, Brooklyn, USA 3. Hematology and Oncology, Brookdale University Hospital \\ and Medical Center, Brooklyn, USA 4. Research Medicine, New York Institute of Technology College of Osteopathic \\ Medicine, New York, USA 5. Primary Care, Touro College of Osteopathic Medicine, New York, USA 6. Oncology, Mont \\ Sinai Medical Center, Brooklyn, USA
}

Corresponding author: Burak Erdinc, berdinc@icloud.com

\begin{abstract}
Humoral hypercalcemia of malignancy (HHM) is most commonly encountered in squamous cell carcinoma (SCC) of different organs, and It is characterized by elevated parathyroid hormone-related peptide (PTHrP) levels. It may be seen as a manifestation of cholangiocarcinoma (CCC) at presentation and later in the course of the disease. However, HHM due to intrahepatic cholangiocarcinoma is a rare association and is associated with a poor prognosis.
\end{abstract}

We herein report a case of hypercalcemia presenting as the first manifestation of an underlying rare variant of intrahepatic cholangiocarcinoma. Our patient is a 57-year-old male who presented to the emergency room with severe symptoms of constipation and polyuria and was admitted to the hospital for symptomatic hypercalcemia. He was found to have a hypermetabolic $15 \mathrm{~cm}$ liver mass, abdominal lymph nodes on imaging, which was subsequently diagnosed as adenosquamous cholangiocarcinoma by liver biopsy. This necessitated an urgent inpatient treatment with gemcitabine/cisplatin combination chemotherapy to control the aggressive nature of the malignancy. However, he deteriorated and expired after three months of his diagnosis.

Adenosquamous cholangiocarcinoma is a very rare variant of a liver tumor. It develops due to squamous metaplasia of an underlying cholangiocarcinoma and usually has aggressive clinicopathological features. HMM is a life-threatening, yet unrecognized, phenomenon of cholangiocarcinoma, which represents a poor prognostic marker. Prompt recognition of this complication is important for preventing serious complications associated with hypercalcemia and to improve the quality of life of these patients.

Received 12/05/2019

Review began 12/06/2019

Review ended 12/25/2019

Published 12/27/2019

() Copyright 2019

Erdinc et al. This is an open access article distributed under the terms of the Creative Commons Attribution License CC-BY 3.0., which permits unrestricted use, distribution, and reproduction in any medium, provided the original author and source are credited.
Categories: Endocrinology/Diabetes/Metabolism, Internal Medicine, Oncology

Keywords: cholangiocarcinoma, humoral hypercalcemia of malignancy, parathyroid hormone related peptide, parathyroid hormone, paraneoplastic syndrome, cholangiocarcinoma

\section{Introduction}

Hypercalcemia of malignancy is seen in up to $30 \%$ of all cancers via four different mechanisms: humoral hypercalcemia of malignancy (HHM), local osteolytic hypercalcemia, excess 1,25(OH)2D secretion, and ectopic parathyroid hormone secretion [1]. Parathyroid hormone-related peptide (PTHrP) secretion is the most common mechanism (80\%) causing hypercalcemia of malignancy [1-2]. Even though HHM theoretically can be seen in any type of cancer, it is very rarely seen with cholangiocarcinoma, as in our case [3].

\section{Case Presentation}

A 67-year-old Hispanic male presented to the emergency department with gradually worsening complaints of generalized body weakness, difficulty sleeping, abdominal pain, increased thirst with urinary frequency, and constipation for the last two months. He had a past medical history of a fatty liver secondary to alcohol use and a four-pack per year smoking history. The initial physical examination was unremarkable with normal vital signs except for hepatomegaly. The laboratory data on admission are summarized in Table 1 . 


\section{Cureus}

\begin{tabular}{|c|c|c|}
\hline & Normal Range & Result \\
\hline White Blood Cell Count & $4.10-10.1010 \times 9 / L$ & $17.60(\mathrm{H})$ \\
\hline Hemoglobin & $12.9-16.7 \mathrm{~g} / \mathrm{dL}$ & 12.7 (L) \\
\hline Mean Corpuscular Volume & $80.8-94.1 \mathrm{fL}$ & 86.5 \\
\hline Platelet Count & $153-32810 \times 9 / L$ & $422(\mathrm{H})$ \\
\hline Absolute Neutrophil Count & $1.40-6.8010 \times 9 / L$ & $12.80(\mathrm{H})$ \\
\hline Absolute Lymphocyte Count & $1.10-2.9010 \times 9 / L$ & 2.60 \\
\hline Absolute Monocyte Count & $0.20-1.0010 \times 9 / L$ & $1.20(\mathrm{H})$ \\
\hline Absolute Eosinophil Count & $0.00-0.4010 \times 9 / L$ & $0.80(\mathrm{H})$ \\
\hline Absolute Basophil Count & $0.00-0.1010 \times 9 / L$ & $0.20(\mathrm{H})$ \\
\hline International Normalized Ratio & $0.70-1.20$ & 1.08 \\
\hline Blood Urea Nitrogen & $9.0-20.0 \mathrm{mg} / \mathrm{dL}$ & 18.0 \\
\hline Creatinine & $0.66-1.25 \mathrm{mg} / \mathrm{dL}$ & 0.94 \\
\hline Sodium & 133 - 145 mEq/L & 134 \\
\hline Potassium & $3.5-5.1 \mathrm{mEq} / \mathrm{L}$ & 4.1 \\
\hline Chloride & $98-107 \mathrm{mEq} / \mathrm{L}$ & $96(\mathrm{~L})$ \\
\hline $\mathrm{CO}_{2}$ & $22-30 \mathrm{mEq} / \mathrm{L}$ & $31(\mathrm{H})$ \\
\hline Calcium & $8.4-10.5 \mathrm{mg} / \mathrm{dL}$ & $15.2(\mathrm{H})$ \\
\hline Phosphorus & $2.5-4.5 \mathrm{mg} / \mathrm{dL}$ & 2.9 \\
\hline Total Protein & $6.3-8.2 \mathrm{~g} / \mathrm{dL}$ & 6.4 \\
\hline Albumin & $3.5-5.0 \mathrm{~g} / \mathrm{dL}$ & 3.4 (L) \\
\hline Total Bilirubin & $0.2-1.3 \mathrm{mg} / \mathrm{dL}$ & 0.5 \\
\hline Alanine Aminotransferase & $21-72 U / L$ & 29 \\
\hline Aspartate Aminotransferase & $17-59 \mathrm{U} / \mathrm{L}$ & 20 \\
\hline Alkaline Phosphatase & $38.0-126.0 \mathrm{U} / \mathrm{L}$ & $141.0(\mathrm{H})$ \\
\hline Gamma-Glutamyl Transferase & $15-73 U / L$ & 276 \\
\hline Magnesium & $1.6-2.3 \mathrm{mg} / \mathrm{dL}$ & 1.4 (L) \\
\hline Parathyroid Hormone0Related Protein & $14-27 \mathrm{pg} / \mathrm{ml}$ & 82(H) \\
\hline Alfa Fetoprotein & $<6.1 \mathrm{ng} / \mathrm{mL}$ & 2.2 \\
\hline Cancer Antigen 19-9 & $<34 \mathrm{U} / \mathrm{mL}$ & $140(H)$ \\
\hline Carcinoembryonic Antigen & $0.0-2.4 \mathrm{ng} / \mathrm{mL}$ & 1.5 \\
\hline Intact Parathyroid Hormone & $14-64$ pg/mL & 2 (L) \\
\hline Vitamin D,1,25-(OH)2 & $18-72 \mathrm{pg} / \mathrm{mL}$ & 31 \\
\hline
\end{tabular}

\section{TABLE 1: Initial laboratory investigations}

The initial laboratory evaluation showed leukocytosis (white blood cell count of 16.60 10x9/L), normal kidney function, elevated corrected calcium level of $15.5 \mathrm{mg} / \mathrm{dL}$, elevated alkaline phosphatase level of 141 $\mathrm{U} / \mathrm{L}$ (normal range 38.0-126.0 U/L), and normal phosphorus level of $2.9 \mathrm{mg} / \mathrm{dl}$ (normal range $2.5-4.5 \mathrm{mg} / \mathrm{dl}$ ). Intact parathyroid level was found to be low at $2 \mathrm{pg} / \mathrm{ml}$ (normal range 14-64 pg/ml). However, parathyroid hormone-related peptide level (PTHrP) was high at $82 \mathrm{pg} / \mathrm{ml}$ (normal range $14-27 \mathrm{pg} / \mathrm{ml}$ ). His other 


\section{Cureus}

laboratory values included low vitamin D,25-Hydroxy level of $13.4 \mathrm{ng} / \mathrm{ml}$ (normal range 30-100 ng/ml), carcinoembryonic antigen (CEA) level of $1.5 \mathrm{ng} / \mathrm{mL}$ (normal range: $<5.0 \mathrm{ng} / \mathrm{mL}$ ), carbohydrate antigen (CA) 19-9 level of $140 \mathrm{U} / \mathrm{mL}$ (normal range: <34 U/mL), $\alpha$-fetoprotein (AFP) level of $1.6 \mathrm{ng} / \mathrm{mL}$ (normal range: < $6.1 \mathrm{ng} / \mathrm{mL}$ ), and serum protein electrophoresis was within normal limits. He had negative viral serology for hepatitis B, hepatitis C, Epstein Barr Virus, cytomegalovirus, and human immunodeficiency virus. A computerized tomography (CT) scan of the abdomen and pelvis with intravenous contrast was performed to evaluate the etiology of abdominal pain, which revealed a large complex appearing mass within the liver appearing as multifocal lesions with a large central hypodense lesion and numerous peripheral satellite lesions; the largest component of the mass measured $19.1 \times 14.7 \mathrm{~cm}$ (Figure 1). There was also mild intrahepatic bile duct dilatation, most likely due to mass-effect on the porta hepatis, and haziness within the fat inferior to the liver, which was concerning for peritoneal carcinomatosis.
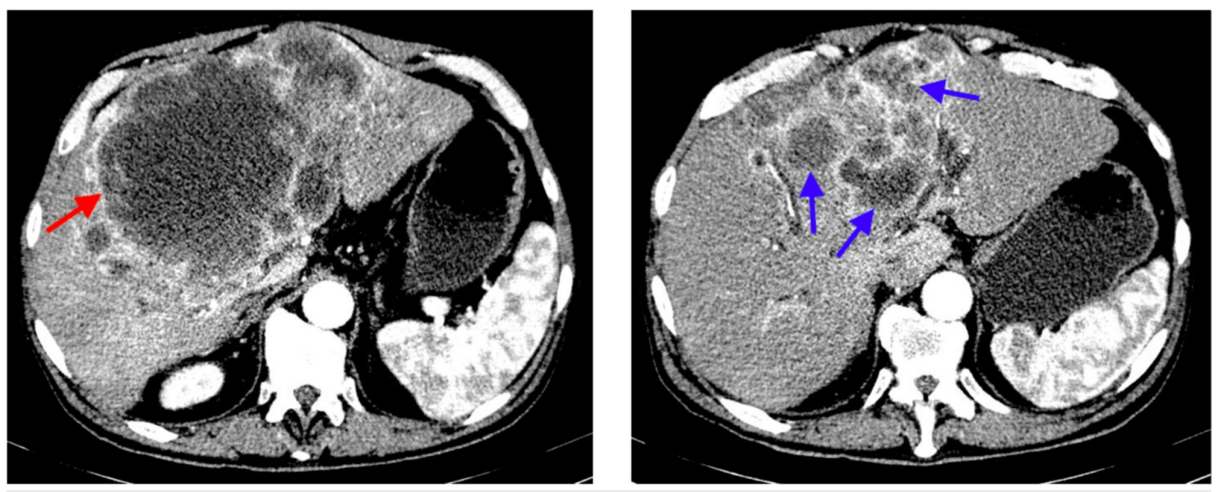

FIGURE 1: Computerized tomography of the abdomen with intravenous contrast showing a large, complex-appearing mass within the liver appearing as multifocal lesions with a large central hypodense lesion (red arrow) and numerous peripheral satellite lesions (blue arrows); the largest component of the mass measured $19.1 \times 14.7 \mathrm{~cm}$

The patient was admitted to the hospital and received treatment with intravenous fluid resuscitation, calcitonin, and zoledronic acid for hypercalcemia of malignancy. Further evaluation with positron emission tomography-computed tomography (PET-CT) reported extensive hyper-metabolic activity in the liver, which corresponded to a large, complex cystic mass and multiple satellite lesions on CT images, consistent with malignancy. In addition, It revealed hypermetabolic, small, and mildly enlarged upper abdominal lymph nodes, mildly hypermetabolic activity in the omentum/peritoneum, and ascites; all these findings were suspicious for metastatic disease. Lastly, there were small scattered pulmonary nodules, which were below the size resolution of PET imaging. CT-guided biopsy of the liver was performed, and pathology showed poorly differentiated adenocarcinoma with squamous features supportive of pancreaticobiliary as primary (Figure 2). Tumor cells were positive for CEA, CK19, P63, CK5/6, focally positive for CK7, and negative for CK20 and hepatocyte stains (Figure 3).

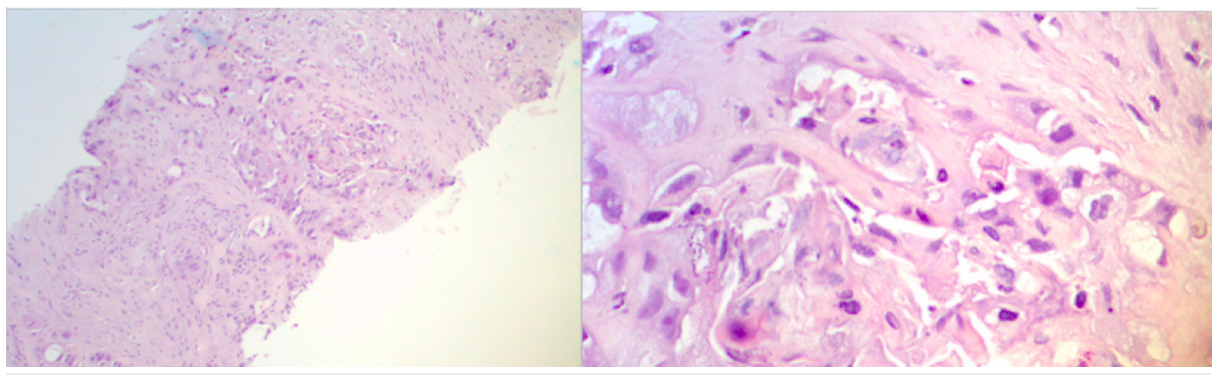

FIGURE 2: Liver core biopsy, H \& E stain, poorly differentiated adenocarcinoma with squamous features (10X on the left and $50 \mathrm{X}$ on the right)

H \& E: hematoxylin and eosin 


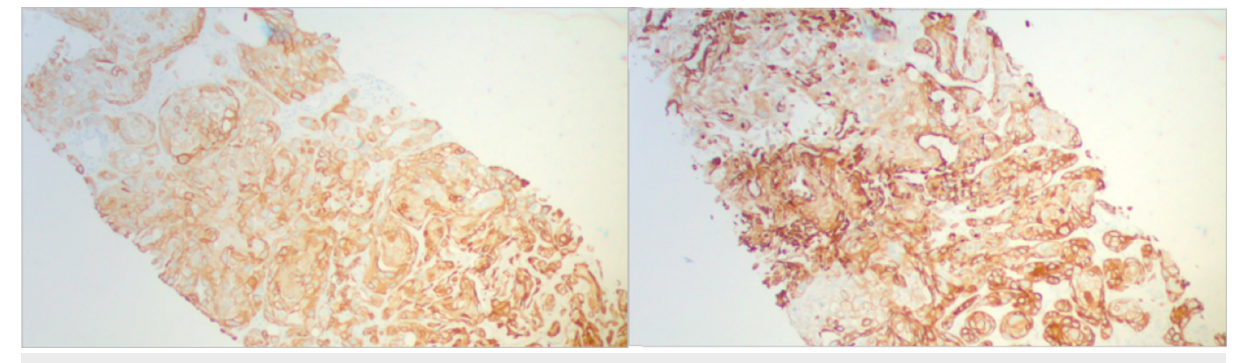

FIGURE 3: Liver core biopsy, 10X. Immunohistochemical stain CK19
positive, favor pancreatic-biliary primary (left). Liver core biopsy, 10X.
Immunohistochemical stain CK5/6 positive, favor squamous features
(right)

Chemotherapy with cisplatin and gemcitabine was started after the diagnosis was confirmed. However, the patient had recurrent admissions with worsening symptoms and uncontrolled hypercalcemia. His course was also complicated further with acute kidney injury, cholestatic hyperbilirubinemia, and pancreatitis and required placement of percutaneous transhepatic cholecystostomy (PTC). The patient's condition further deteriorated, and he expired within three months of his diagnosis.

\section{Discussion}

Cholangiocarcinoma is a very aggressive tumor and comprises about $3 \%$ of all gastrointestinal malignancies [4]. Studies on this rare type of tumor are only limited to case reports or small case series [2,5-6]. Primary sclerosing cholangitis (PSC), fibropolycystic liver disease, hepatolithiasis, chronic viral hepatitis, and a few genetic conditions, such as Lynch syndrome, BRCA-associated protein-1 (BAP1) tumor predisposition syndrome, cystic fibrosis, and biliary papillomatosis are among the common risk factors for cholangiocarcinoma [7]. Toxic exposure to thorotrast (previously used radiocontrast agent) [8], parasitic infections with Clonorchis and Opisthorchis [9], and human immunodeficiency virus (HIV) infection [10] have also proved to have a relationship with cholangiocarcinoma.

Adenosquamous cholangiocarcinoma (ASC) is a rare variant of cholangiocarcinoma, which was first described by Barr and Hancock in 1975 [11] and consists of malignant glandular and squamous components. Tumor cells have both mucin-producing glandular structures as in adenocarcinoma and irregularly shaped solid nests of polygonal cells with distinct cellular borders, eosinophilic cytoplasm, varying degrees of keratinization, and intercellular bridges as in squamous cell cancer [12-13]. Cholangiocarcinoma with squamous features have been previously described as ASC but also as mucoepidermoid carcinoma (mucusproducing cells and squamoid cells without keratin formation) and adenoacanthoma (squamous metaplasia) $[6,14]$. The prognosis of ASC is extremely poor even with surgery and most patients are not candidates for surgery and chemotherapy at presentation $[2,6,12]$. Nakajima and Kondo [2] evaluated 11 patients with ASC and compared their prognosis with 82 cholangiocarcinoma patients with adenocarcinoma features and found that the mean overall survival was four months in ASC patients versus 6.9 months in the latter.

HHM is caused by PTH-related peptide (PTHrP) by malignant tumors, such as squamous cell carcinoma, renal cell carcinoma, ovarian cancer, endometrial cancer, lymphoma, and breast cancer [1]. PTHrP has different identified functions, such as proliferation and differentiation in chondrocytes [15], regulation of calcium level in the placenta [16], calcium reabsorption in renal cells, resorption of calcium from osteocytes [17], and browning of adipose cells and cachexia [18-19]. PTHrP secreting cancer cells can be detected, for diagnostic and research purposes, with immunohistochemical stains (PTHrP antibody stain). Even though HMM has been previously described in different types of cancers, it is an unrecognized phenomenon of cholangiocarcinoma and associated with a very poor prognosis [20]. For this reason, the early detection and treatment of HHM is essential. The treatment of HHM should include immediate treatment with intravenous hydration and calcitonin and long-term treatment with bisphosphonates and denosumab. Hemodialysis is usually reserved for patients with severe hypercalcemia.

\section{Conclusions}

Our case is an example of metastatic adenosquamous cholangiocarcinoma without bony metastasis, presenting as hypercalcemia, secondary to PTHrP levels confirming the diagnosis of HHM. Adenosquamous cholangiocarcinoma, being a very rare variant of cholangiocarcinoma presents with HHM, which is also a very rare presentation, as it is usually associated with other types of cancers. Physicians should be aware of this rare presentation of cholangiocarcinoma, as prompt recognition of this atypical presentation can prevent the serious complications associated with hypercalcemia and improves the quality of life of these patients. 


\section{Additional Information \\ Disclosures}

Human subjects: Consent was obtained by all participants in this study. Conflicts of interest: In compliance with the ICMJE uniform disclosure form, all authors declare the following: Payment/services info: All authors have declared that no financial support was received from any organization for the submitted work. Financial relationships: All authors have declared that they have no financial relationships at present or within the previous three years with any organizations that might have an interest in the submitted work. Other relationships: All authors have declared that there are no other relationships or activities that could appear to have influenced the submitted work.

\section{References}

1. Stewart AF: Hypercalcemia associated with cancer. N Engl J Med. 2005, 352:373-379. 10.1056/NEJMcp042806

2. Nakajima T, Kondo Y: A clinicopathologic study of intrahepatic cholangiocarcinoma containing a component of squamous cell carcinoma. Cancer. 1990, 65:1401-1404. 10.1002/10970142(19900315)65:6\%3C1401::AID-CNCR2820650626\%3E3.0.CO;2-K

3. Yamada M, Shiroeda H, Shiroeda S, Sato K, Arisawa T, Tsutsumi M: Cholangiocarcinoma producing parathyroid hormone-related peptide treated with chemoradiation using gemcitabine and S-1. Intern Med. 2009, 48:2097-2100. 10.2169/internalmedicine.48.2644

4. Vauthey J, Blumgart LH: Recent advances in the management of oncologic pain . Curr Probl Cancer. 1989, 13:135-196. 10.1016/0147-0272(89)90011-1

5. Yeh C-N, Jan Y-Y, Chen M-F: Adenosquamous carcinoma of the liver: clinicopathologic study of 10 surgically treated cases. World J Surg. 2003, 27:168-172. 10.1007/s00268-002-6585-0

6. Maeda T, Takenaka K, Shirabe K, et al.: Adenosquamous carcinoma of the liver. Clinicopathologic characteristics and cytokeratin profile. Cancer. 1997, 80:3-364. 10.1002/(SICI)10970142(19970801)80:3\%3C364::AID-CNCR3\%3E3.0.CO;2-S

7. Chapman RW: Risk factors for biliary tract carcinogenesis . Ann Oncol. 1999, 10:308-311. 10.1093/annonc/10.suppl 4.S308

8. Sahani D, Prasad SR, Tannabe KK, Hahn PF, Mueller PR, Saini S: Thorotrast-induced cholangiocarcinoma: case report. Abdom Imaging. 2003, 28:72-74. 10.1007/s00261-001-0148-y

9. Watanapa P, Watanapa WB: Liver fluke-associated cholangiocarcinoma. Br J Surg. 2002, 89:962-970. 10.1046/j.1365-2168.2002.02143.x

10. Shaib YH, El-Serag HB, Davila JA, Morgan R, McGlynn KA: Risk factors of intrahepatic cholangiocarcinoma in the United States: a case-control study. Gastroenterology. 2005, 128:620-626. 10.1053/j.gastro.2004.12.048

11. Park SY, Cha EJ, Moon WS: Adenosquamous carcinoma of the liver. Clin Mol Hepatol. 2012, 18:326-329. 10.3350/cmh.2012.18.3.326

12. Kobayashi M, Okabayashi T, Okamoto K, Namikawa T, Araki K: A clinicopathologic study of primary adenosquamous carcinoma of the liver. J Clin Gastroenterol. 2005, 39:544-548. 10.1097/01.mcg.0000165705.74079.fc

13. Park SY, Cha EJ, Moon WS: Adenosquamous carcinoma of the liver. Clin Mol Hepatol. 2012, 18:326-329. 10.3350/cmh.2012.18.3.326

14. Pianzola LE, Drut R: Mucoepidermoid carcinoma of the liver. Am J Clin Pathol. 1971, 56:758-761. 10.1093/ajcp/56.6.758

15. Karaplis AC, Luz A, Glowacki J, Bronson RT, Tybulewicz VL, Kronenberg HM, Mulligan RC: Lethal skeletal dysplasia from targeted disruption of the parathyroid hormone-related peptide gene. Genes Dev. 1994, 8:277-289. 10.1101/gad.8.3.277

16. Rodda CP, Kubota M, Heath JA, et al.: Evidence for a novel parathyroid hormone-related protein in fetal lamb parathyroid glands and sheep placenta: comparisons with a similar protein implicated in humoral hypercalcaemia of malignancy. J Endocrinol. 1988, 117:261-271. 10.1677/joe.0.1170261

17. Stewart AF: Hypercalcemia associated with cancer. N Engl J Med. 2005, 352:373-379. 10.1056/NEJMcp042806

18. Kir S, Spiegelman BM: Cachexia and brown fat: a burning issue in cancer . Trends Cancer. 2016, 2:461-463. 10.1016/j.trecan.2016.07.005

19. Guntur AR, Doucette CR, Rosen CJ: PTHrp comes full circle in cancer biology . Bonekey Rep. 2015, 4:621. 10.1038/bonekey.2014.116

20. Wright JD, Tergas AI, Ananth CV, et al.: Quality and outcomes of treatment of hypercalcemia of malignancy . Cancer Invest. 2015, 33:331-339. 10.3109/07357907.2015.1047506 